\title{
U.S. wildfire governance as social-ecological problem
}

\author{
Toddi Steelman ${ }^{1,2}$
}

ABSTRACT. There are fundamental spatial and temporal disconnects between the specific policies that have been crafted to address our wildfire challenges. The biophysical changes in fuels, wildfire behavior, and climate have created a new set of conditions for which our wildfire governance system is poorly suited to address. To address these challenges, a reorientation of goals is needed to focus on creating an anticipatory wildfire governance system focused on social and ecological resilience. Key characteristics of this system could include the following: (1) not taking historical patterns as givens; (2) identifying future social and ecological thresholds of concern; (3) embracing diversity/heterogeneity as principles in ecological and social responses; and (4) incorporating learning among different scales of actors to create a scaffolded learning system.

Key Words: environmental governance; institutions; policy; scale; social-ecological system; United States; wildfire

\section{INTRODUCTION}

Wildfire governance in the United States faces significant challenges. Key goals, as articulated in major policy documents since 1995, are not being met. These goals include the following:

1. Restore fire adapted ecosystems (USDA and USDOI 1995, $2000 a, b, 2001,2003,2009 a, b$, WGA 2001, 2002, USFS $2003 a$, USFS, USDOI BLM, NPS, BIA, and NASF 2005, 2009, USFS 2009a,b);

2. Build fire adapted communities (USDA and USDOI $2000 a$, $b$, , 2009b, WGA 2001, 2002, USFS 2003a, USFS, USDOI BLM, NPS, BIA, and NASF 2005, 2009);

3. Respond appropriately to wildfire (USDA and USDOI 1995, 2000a,b, 2003, 2001, 2009a,b, WGA 2001, 2002, USFS, USDOI BLM, NPS, BIA, and NASF 2005, 2009, USFS 2009a);

4. Reduce hazardous fuels (USDA and USDOI $2000 a, b, 2006$, WGA 2001, 2002, 2009b, USFS 2002, 2003a,b, 2009b, USFS, USDOI BLM, NPS, BIA, and NASF 2005, 2009);

5. Engage in agency coordination and community cooperation (USDA and USDOI 2000a,b, 2006, 2009b, WGA 2002, 2003, USFS, USDOI BLM, NPS, BIA, and NASF 2009).

Tens of millions of acres on U.S. National Forest and Department of Interior lands are at risk because they are out of step based on their current fire regime (Schmidt et al. 2002, USFS 2012a). Funding is inadequate for the scale of the restoration problem (US GAO 2009, Gorte and Bracmort 2012). While we are focusing on building fire adapted communities in terms of prioritizing treatment in the wildland urban interface (WUI; USFS 2012b, 2013), we are still losing more structures over time. We are spending more money to respond to wildfire (Gorte 2011, USFS 2009c, 2010, 2011, 2012a, 2013, 2014, 2015), seeing more fatalities (NWCG 2014) and missing the mark in terms of estimated cost per acre to suppress wildfire (USFS 2013, 2014). Given the lack of progress on these fronts, in conjunction with the enormous commitment of resources estimated at $\$ 1-4$ billion annually (all figures in U.S. dollars; Gorte 2011, USFS Budget Justification $2009 c, 2010,2011,2012 a, 2013,2014,2015)$, it is reasonable to ask why and whether we are framing the problem appropriately to understand it fully.

Understanding wildfire governance as part of a broader socialecological system is helpful in this regard. One hypothesis about why wildfire governance does not function as well as it could may be because the biophysical changes in fuels, wildfire behavior, and climate have created a new set of conditions for which our existing governance structures are poorly suited to address (Moritz et al. 2014, Spies et al. 2014), problems not unique to the realm of wildfire (Cash et al. 2006, Folke et al. 2007, Young et al. 2008, Meek 2011). When we see historically stable ecological processes tipping toward a shift, governance systems are often unprepared to deal with such rapid and large-scale change (Gunderson et al. 1995). Wildfire regimes globally may be tipping toward such change (Attiwill and Binkely 2013). The inability to match ecological changes with appropriate governance structures can be attributed to limited knowledge about how they fit their ecological systems, the sheer complexities of social-ecological systems that result in entrenched uncertainties, and ingrained interests resisting change, or the basic challenge of institutional reform (Young et al. 2008). More work is needed to understand wildfire as a social-ecological problem (Moritz et al. 2014, Spies et al. 2014, Fischer et al. 2016).

In this article I address two research questions:

- To what extent do the spatial and temporal scales of our wildfire governance system fit the social-ecological dynamics that drive the system?

- What could we do to improve wildfire governance if we were to embrace social-ecological dynamics?

To address these questions, the article employs a social-ecological framework developed by Chapin et al. (2006) and further used by Meek (2011) to illustrate the importance of spatial and temporal scales in analyzing a policy context. Using wildfire governance in the United States, the article "maps" social and ecological factors, at various scales of organization according to three levels of temporal dynamics: exogenous; slow and fast to better understand the goodness of fit in wildfire-related governance in the US.

${ }^{1}$ School of Environment and Sustainability, University of Saskatchewan, ${ }^{2}$ North Carolina State University, Department of Forestry and Environmental Resources 
Fig. 1. Wildfire governance in a social-ecological framework.

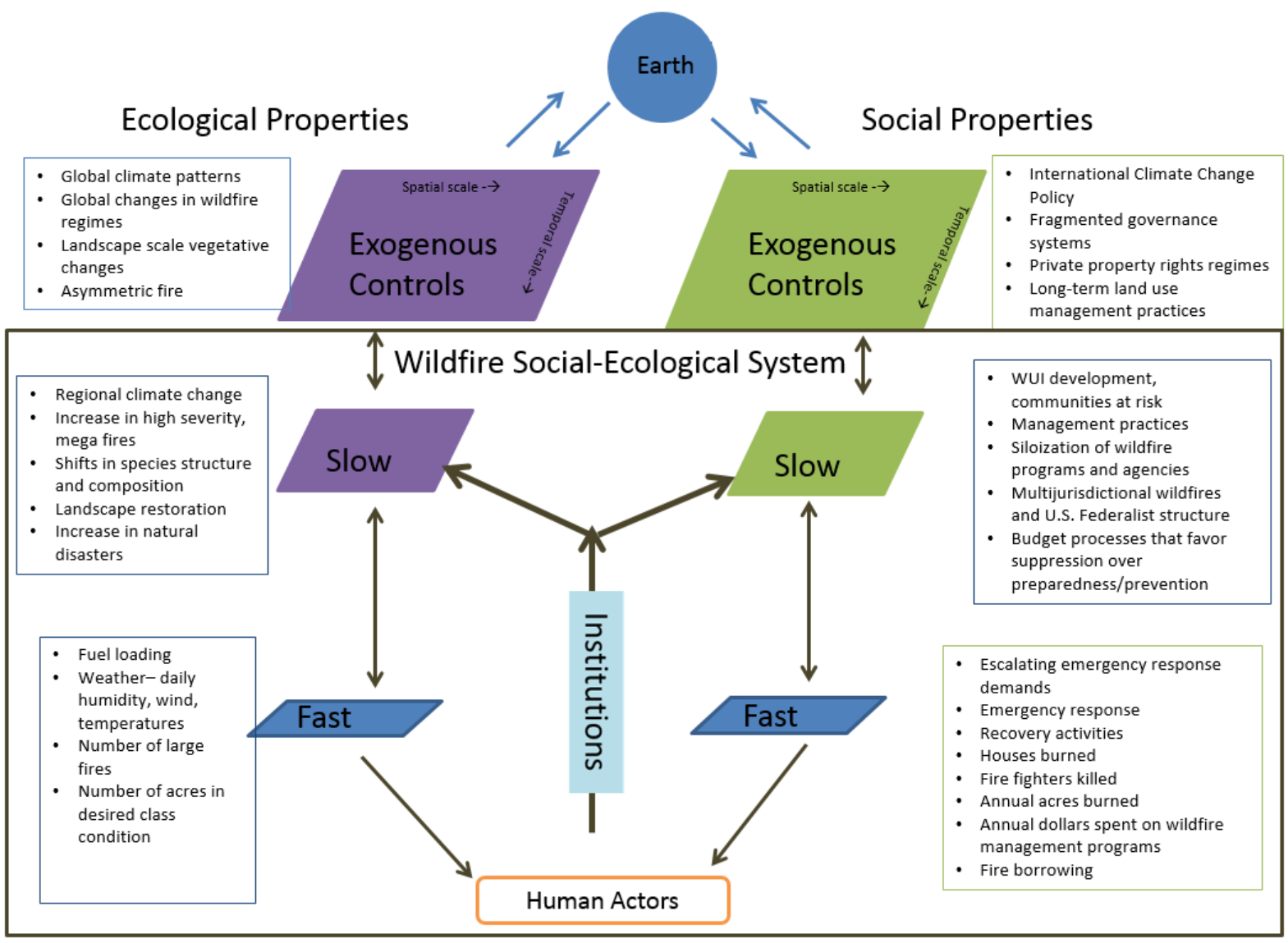

\section{WILDFIRE GOVERNANCE WITHIN A SOCIAL- ECOLOGICAL SYSTEM}

Wildfire governance is embedded within a wildfire socialecological system. Understanding wildfire governance as part of a complex social-ecological system allows for greater consideration of the cross-scale and temporal dynamics that typify real life complexities of human-environment problems (Liu et al. 2007). This social-ecological analysis can facilitate the identification of key areas of vulnerability while identifying areas of adaptability for greater long-term social and ecological resilience.

Building on a framework advanced by Chapin et al. (2006) and utilized by others (cf. Meek 2011), I illustrate wildfire governance as part of a social-ecological system (SES; Fig. 1). This system comprises ecological and social subsystems along with the wildfire governance system, which mediates response between these two interacting subsystems. Both the ecological and social subsystems are influenced by exogenous controls, which are comparatively constant over long time periods, 100 years or more, as well as slow and fast moving variables (Chapin et al. 2006). Slow variables would be relatively constant over decades or longer, while fast variables would change daily, seasonally, or yearly (Chapin et al. 2006). Slow variables will influence fast variables, and vice versa.
The cumulative impact of change in a fast variable can create a feedback to alter a slow variable and ultimately the exogenous control within and across these systems.

The wildfire governance system mediates how we respond to wildfire in the U.S. Governance also has important spatial and temporal dimensions that influence how we should think about wildfire from a SES perspective. Spatially, as a federated system, governance in the U.S. is nested at the local, state, and federal levels. A variety of public, private, nonprofit, and research-based actors play a role in governance at all of these levels.

Institutions or rules and norms shape behavior at levels of governance (Duit and Galaz 2008). Policies, strategies, and programs may be formally adopted at different levels of governance, but may take a long time to become institutionalized. For instance, while U.S. federal policy has formally recognized the importance of allowing wildfire to play an increased ecological role on the landscape, a culture of suppression has been more institutional at the federal, state, and local levels. These temporal dimensions are important because they have implications for our expectations for change. Policies can become institutionalized if they become part of the norms, habit, and practice within a governance system (Young et al. 2008). 
Ideally, we would like alignment between our policies and their longer term effects as institutions. In the short term, policies may play a formal, symbolic role in effecting change, while not actually affecting behavior change. Even if policies become institutionalized, other factors may affect their ability to effect change, especially in SES (Underdahl 2008, Young et al. 2008). In some cases the policies institutionalized to address socialecological problems may not be the most important drivers in environmental or natural resource change. Institutions are affected by a variety of other drivers in social-ecological systems (political dynamics, cultural change, economic trends, demographic conditions, and technology) as well as patterns and trends in biophysical phenomena that may be resistant to or overwhelm any impact an institution may have. Conclusively isolating their singular impact on a given problem is fraught with analytical and methodological challenges (Young et al. 2008). Nonetheless, policies and institutions within our complex governance systems are one means we have for addressing problems in our social-ecological systems and understanding drivers, pathways, patterns, and effects is a way to advance the discussion about the complexities we face as a society, and the inevitable choices we need to make to manage these complexities. Creating a full picture of how different factors contribute to a given problem area while recognizing the considerable uncertainties that are present, is at least a starting point for having a more full dialogue about what matters, why, and what can and should be done about it.

Fit and interplay have been identified as key issues essential for evaluating the efficacy of policies and institutions within governance structures (Young et al. 2008). Ideally, we would like to see a good fit between the institutions governing socialecological systems and their characteristics and attributes (Folke et al. 2007, Termeer et al. 2010). A plausible hypothesis for when we encounter policy or institutional failure is to look to temporal and spatial scale mismatch as a potential explanation. There is cross scale interaction within the governance system and so we would expect that laws and policies regulating ecological change would likewise have an impact on social policies, norms, and behaviors. Scale has more recently come to the attention of scholars investigating institutional and policy dimensions (Olsson et al. 2007, Young et al. 2008, Duit et al. 2010, Gerlak 2014). In a federated system, the creation of policy goals at a national level inevitably intersect at the most local level where change actually happens. Consequently, scale becomes an important consideration for evaluating the efficacy of governance systems (Termeer et al. 2010).

\section{The social-ecological system}

Exogenous controls are stable factors that are not influenced easily by short term changes. In wildfire governance, we have ecological and social exogenous controls (Fig 1). These exist at larger spatial scales and longer temporal scales than the slow and fast variables, which would operate at smaller scales over shorter time frames. Among the spatial and temporal scales, there is often little opportunity to connect or learn from one level to the next to create a more integrated understanding of how cycles and process at one level influence behaviors and actions at another level.

Ecological exogenous controls within the wildfire regime include global climate patterns, wildfire regimes, and landscape scale vegetation change. Some evidence suggests that these exogenous controls greatly constrain governance options for affecting fire characteristics (Moritz et al. 2014). Globally we continue to witness increases in total greenhouse gas emissions, which are contributing to rising global temperatures (IPCC 2014a, Olivier et al. 2014). Increases are being driven by fossil fuel combustion and industrial processes, which in turn are driven by population and economic growth (IPCC 2014a). The use of coal, particularly in China and India, has reversed the trend toward decarbonization of the global energy supply (IPCC 2014a). Given these trends and the conditions driving them, the Intergovernmental Panel on Climate Change (IPCC) projects that global mean surface temperatures will increase by $3.7^{\circ} \mathrm{C}$ to $4.8^{\circ}$ $\mathrm{C}$ compared to preindustrial levels, provided additional mitigation measures are not taken (IPCC 2014b). Climate change models suggest that more severe fire seasons will be experienced in the northern hemispheres generally (Flannigan et al. 2013) as well as specifically in Canada (Flannigan et al. 2009), the Mediterranean Basin (Moriondo et al. 2006, Moreira et al. 2011), and the United States (Liu et al. 2013). Globally we are seeing changes in "mega fire" wildfire activity (Attiwill and Binkley 2013). Climate influences vegetation and hence fire regimes (Moritz et al. 2012). Major landscape level changes in forest vegetation are predicted globally (Stephens et al. 2013). Evidence indicates that historical wildfire regimes varied greatly across North America until fire management practices altered these regimes (McKenzie et al. 2004).

Social exogenous controls include international climate change institutions (The United National Framework Convention on Climate Change and the Kyoto Protocol) or lack thereof (Victor 2004), the U.S. federalist structure that fragments wildfire governance at the local, state, and national level (Fleming et al. 2015), and dominance of private property rights regimes that place a primacy on the individual's right to manage their property as they like as opposed to a more collective norm (Ferrier 1995), and long-term land use management practices such as fire suppression, grazing, and logging that have contributed to our existing landscape patterns (Dombeck et al. 2004, Kaufmann 2004). The human preference for suppression over fire for resource benefits has had a long lasting impact on the landscape and will continue to do so (Noss et al. 2006). Both the ecological and social exogenous controls constitute forces or drivers in this broader system that are more resistant to change than the slow and fast moving variables in the ecological and social subsystems.

The ecological subsystem

Slow variables

For the purposes of this article, slow variables occur on a decade's level temporal scale and over a regional spatial scale. Climate conditions are leading to regional increases in wildfire in the U. S. with projections by U.S. Forest Service (USFS) wildfire management that suggest we could hit norms of 10-12 million acres annually (USFS, US DOI BLM, NPS, BIA and NASF 2009). Earlier melting and smaller snow packs, lower humidity, and higher temperatures are predicted to lead to longer wildfire seasons and greater risk of wildfire in the longer term across the western United States. Warmer temperatures appear to be correlated with longer wildfire seasons in the western U. S., which is dominated by a snow hydrology (Running 2006, Westerling et al. 2006). Earlier melting snow packs combined with higher 
temperatures and lower humidity lead to the greater probability of wildfire risk. That said, model projections differ based on their assumptions and consequent regional effects. Some suggest we can expect lower humidity and thus greater fire danger in the northern Rockies, Great Basin, and desert Southwest into the 21st century (Brown et al. 2004). Others find that the Southwest, Rocky Mountains, northern Great Plains, Southeast and Pacific coast, but not the northern Rocky Mountains will experience pronounced increases in wildfire activity (Liu et al. 2013). Globally, far term models suggest that fire will increase in midto high latitudes (Moritz et al. 2012).

We are seeing evidence that fire ecosystems are trending toward nonlinear change in some places-what fire managers in the United States have termed "asymmetric fire" or fire behavior and patterns unprecedented in recent history (USFS, USDOI BLM, NPS, BIA, and NASF 2009, Attiwill and Binkely 2013, Liu et al. 2013). Under these conditions, it is important to understand that historical conditions upon which many models are built may not provide effective prediction for future events. New thresholds of concern, such as unusual fire behavior, may provide triggers for considering alternatives for future action in the absence of predictive models, especially when multiple drivers are present. Although a particular fire can be driven by ignition sources (human or natural), weather on a given day, live and dead fuel characteristics, and vegetation structure and composition (Reinhardt et al.2008), climate change drives these responses both in the short and longer term. The decreases in humidity, rising temperatures, increases in drought and higher fuel loads are contributing to the rise of mega fires due to the confluence of these various ecological conditions. Arizona, Colorado, and New Mexico have all seen historically large wildfires in the last decade (Attiwill and Binkley 2013). These mega fires are less than $1 \%$ of all total fires but account disproportionately for the total expenditures on wildfire and area burned in the United States (Williams 2013).

Forest landscapes are changing in the United States and this in turn will affect the fire regimes in different areas and the management activities appropriate to address them. Recognizing heterogeneity within and across landscapes is important (Moritz et al. 2014). Because of this high variability different fuel reduction and restoration practices should be taken into consideration in different regions (Schoennagel et al. 2004). For instance, Southwestern ponderosa pine (Pinus ponderosa) forests are adapted to low intensity fire and will require diverse restoration prescriptions that incorporate young tree thinning and the reintroduction of fire (Allen et al. 2002). These prescriptions are inappropriate for low frequency, high intensity forest fire regimes (Allen et al. 2002). Fire regimes in the US are affected by a combination of topography, forest type, climate, fuels, and ignition sources (McKenzie et al. 2004, Schoennagel et al. 2004). For instance, fire suppression as a management tool is thought to have had minimal effects on high severity, infrequent fire regime forests compared to low intensity, frequent fire regime forests (Noss et al. 2006). Mitigation is recommended in areas with high frequency, low to moderate severity fire regimes, while adaptation is suggested in those forests that traditionally have experienced low-frequency, high severity fire regimes (Stephens et al. 2013). For instance, mitigation actions might entail restoring to historical forest structure patterns, while adaptation might anticipate changes in landscape structure, including transitions to nonforest vegetation. Changing vegetative species composition likewise could create greater vulnerabilities for threatened and endangered species because of habitat vulnerabilities in changing forest systems (McKenzie et al. 2004). Alternatively, increased fire presence could also enhance habitat in areas where fire has been excluded, thereby helping threatened and endangered species (McKenzie et al. 2004).

\section{Fast variables}

Fast variables occur at a daily, seasonal, and yearly temporal scale and would include things like, drought, humidity, bug kill, and high temperatures that all interact to create conditions conductive to greater wildfire threats. The cumulative effect of shorter winters and warmer, drier summers will be longer fire seasons (USFS, USDOI BLM, NPS, BIA, and NASF 2009). A changing climate means more days of higher fire danger due to low humidity as well as greater precipitation in the United States (Brown et al. 2004). Wetter years promote fuel loading, while drier years create favorable conditions for burning. The larger amounts of biomass on the landscape from bark beetles and growing conditions that outstrip our ability to reduce fuels that occur under conditions of lower humidity mean we have faster drying vegetation and higher fuel loads that then drive seasonal fire behavior. Hence we are experiencing more large wildfires with irregular patterns. As a consequence, we may be seeing fewer fires, but more acres burn over time (NIFC 2014).

\section{The social subsystem}

The scope and scale of the ecological system can differ significantly from the patterns and approaches in the social system. This is a problem of fit (Young 2002, Olsson et al. 2007, Young et al. 2008). While we witness evidence of a shift in the ecological subsystem, it is not clear that we are seeing a similar shift to accompany this in the social subsystem. Understanding how social and ecological trends are or are not coevolving is an important step in crafting an effective governance response.

Slow variables

Expansion of the wildland urban interface drives the need to protect homes, places wildfire fighters in danger, and inflates the cost of wildfire (Gude et al. 2013, Fischer et al. 2016). Enormous total property values are at risk. Botts et al. (2013) estimate that $1,262,022$ residential properties valued at $\$ 189$ billion in the West are currently listed as at high or very high risk from wildfire threat. If additional properties in close proximity to those properties at high and very high risk are also taken into consideration, the total properties exposed to risk climbs to over 3 million with an estimated value of $\$ 444$ billion (Botts et al. 2013). The southern Rockies and the south central U.S. (CO, AZ, OK, TX) have the most potential properties, as well as the greatest property value, at risk (Botts et al. 2013).

Future thresholds, such as catastrophic loss of life or property, if crossed, could trigger new action, but thus far the system has been resilient to change. Political dynamics are such that wildfire in WUI areas with high values of private property at risk demand a response (Calkin et al. 2015). Some estimate that between 50 $95 \%$ of firefighting costs are driven by the protection of private property (USDA OIG 2006, Gude et al. 2008). Of the 115 million single family homes in the U.S., $40 \%$ are located in the WUI 
Fig. 2. U.S. wildfire funding to protect federal lands, fiscal years 1999-2015 (U.S. dollars). Each agency total is the sum of: Wildfire Management Accounts for Preparedness, Suppression, Hazardous Fuels and Site Rehabilitation, American Recovery and Reinvestment Act Fund, Additonal Appropriations, Use of Emergency Funds, and Use of Prior Year Funds.

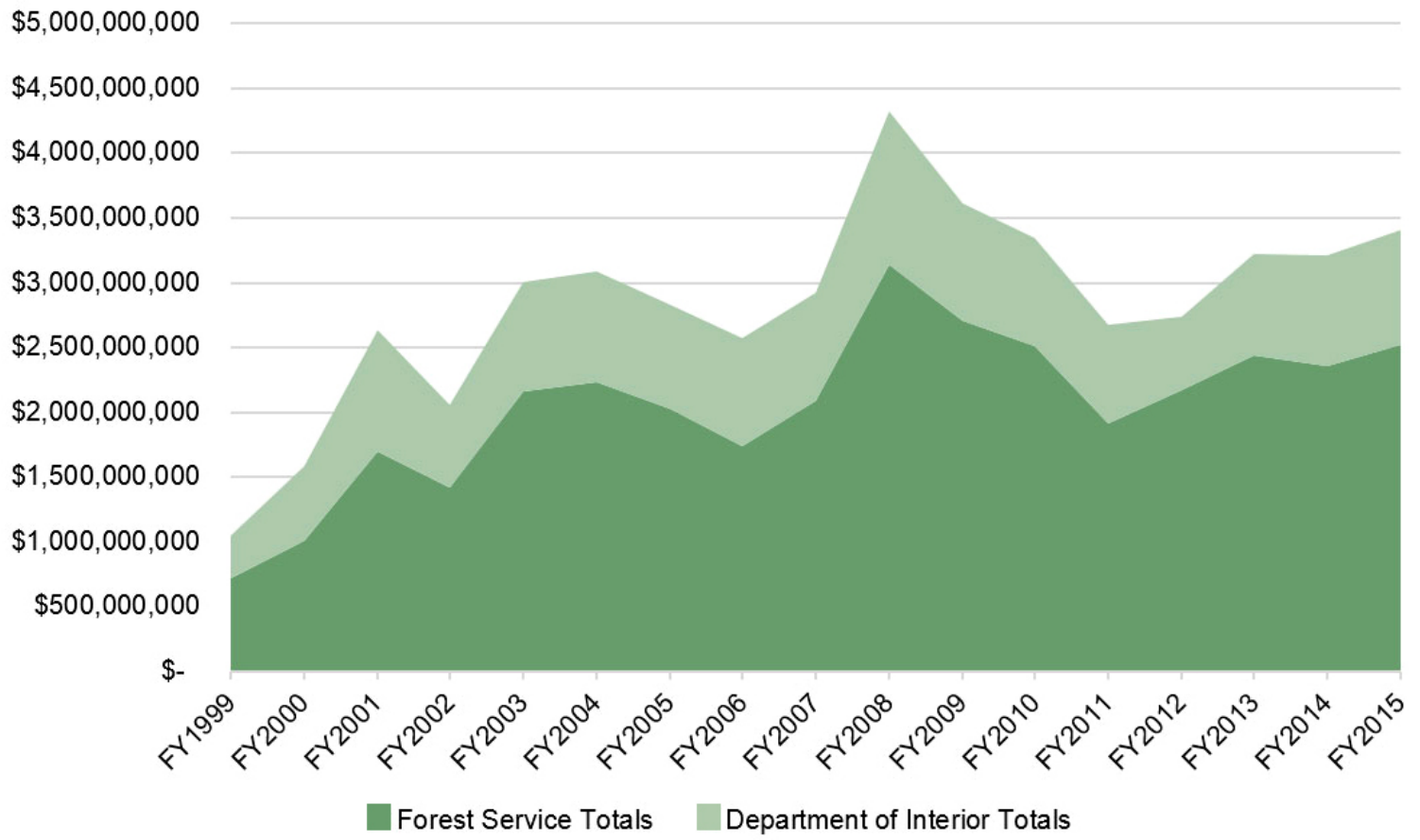

(International Code Council 2008). Between 1990 and 2008, 17 million new homes were built in the U.S. and 10 million of them were in the WUI (Rocky Mountain Insurance Information Association 2012). Only 16\% of the WUI is currently developed (Gorte 2013, Gude et al. 2013), and expansion into the WUI is projected to continue. As of 2014, the U.S. economy was recovering, which means the temporary slowdown in homebuilding is now reversing (National Association of Home Builders 2014).

Managerial culture as well as budget processes have historically favored suppression over prevention and preparation, including the use of prescribed wildfire (Saveland et al. 1988, Pyne 1997, Steelman and Burke 2007). These management and budget decisions have created an overly homogenized landscape vulnerable to large scale wildfire. The current agency budget structure and Congressional appropriations processes prioritize suppression and preparation for suppression activities, including aviation resources and training. The siloization of suppression activities from prevention and preparation activities further reinforces this disconnect. Response activities, especially for large wildfire events, are increasingly occurring at the national level, while preparation and prevention activities are encouraged at the local level (cf. USDA and USDOI 2009b).

Wildfire accounts have been chronically underfunded since 2000 , which has the cumulative effect of impeding the ability of the USFS to manage its lands. For instance, fire protection funding now takes a larger proportion of the total rising from $25 \%$ throughout the 1990 s to $56 \%$ in 2008 (Gorte 2013). A 10-year rolling average suppression funding formula is used to fund the annual suppression budget. Because we are witnessing historic change in wildfire (exogenous and slow ecological variables), past trends are more problematic for forecasting future trends. The current 10-year average formula has resulted in underfunding for suppression activity since 2000 .

Within the United States there is cultural resistance to talk about climate change as a driver related to wildfire processes. The hardening of ideological lines is a significant impediment to creating a learning culture that can adapt as changes occur at different scales. Opinions about climate change are politically polarized in the United States. Liberals and Democrats are more likely to support that climate change is human caused, while Conservatives and Republicans are more skeptical (McCright and Dunlap 2011). Republicans see the issue as hinging on scientific uncertainty with grave economic consequences while Democrats emphasize the catastrophic consequences of a climate crisis (Nisbet et al. 2013). The difficulties associated with this polarized political discussion mean that it is especially challenging to address the larger drivers associated with wildfire processes.

Fast variables

Fast variables tend to focus on those day to day, seasonal or yearly indicators, and policy tends to emerge in response to these fast variables. Fast variables may become the best indicators that social 
thresholds have been crossed because they tend to receive the most attention. Media responses to large fire disasters focus on houses lost, firefighter deaths, and total acres burned, which then place policy focus on the shortfalls of emergency management (Williams 2013) or increase attention to emergency response (Liu et al. 2013). There is little discussion about whether total acres burned are a positive or negative indicator in terms of desired system response. Rather, more acres burned are seen as a negative. More structures are being lost over time, which exacerbates the suppression response. Increases in building in the WUI and the values at risk there (slow variables) are likely driving this trend (Calkin et al. 2015, Fischer et al. 2016). This leads to annual increases in suppression budgets, versus increases in preparedness and prevention budgets, which then limits the ability to respond to the underlying land management problem (Calkin et al. 2015, Fischer et al. 2016).

Throughout the 1990s, total wildfire appropriations averaged $\$ 1.39$ billion annually in real dollars (Gorte 2013). Beginning in the early 2000s, appropriations reached $\$ 3.51$ billion annually (Gorte 2013). Total appropriations to all wildfire accounts rose steadily in the 2000s and flattened out in the 2010s, albeit at a higher plateau than in the 1990s and earlier (See Fig. 2). Annual costs rose more for the USFS than the Department of the Interior (DOI), which has a more flexible fire management mission that allows wildfire to play a more natural role on the landscape and arguably has less WUI to protect than occurs on or near USFS lands (Fleming et al. 2015). Costs often ended up exceeding appropriations because of over expenditures on account of increased and unanticipated fire activity in suppression.

These shortfalls have resulted in almost annual additional Congressional and agency emergency financial intervention to remedy the shortfalls. Fire borrowing from nonsuppression accounts has occurred to make up the deficits in some years. The DOI and USFS saw more than $\$ 3$ billion transferred from nonsuppression accounts between 1999 and 2006 (USFS, USDOI BLM, NPS, BIA, and NASF 2009). In 2004, the Government Accountability Office (GAO) documented numerous cases where fire borrowing disrupted existing prevention projects, strained relationships with local partners, and created management difficulties (US GAO 2009). Programs such as the Forest Land Enhancement Program were terminated by Congress because of fire borrowing. Congress has also borrowed from the KnutsonVandenberg Fund, which was established for forest restoration. Fire borrowing affects the ability to engage more effectively in preparedness activities, such as hazardous fuel reduction.

In addition to disrupting potential projects to reduce risk prior to wildfire season, high suppression costs in the WUI have also increased costs to states and localities, which are responsible for wildfire management on state and private lands. State and local governments spending on wildfire is significant. Out of the total state forestry agencies expenditures in 2010 (\$2.4 billion), 59\% went toward wildfire programs (NASF 2012). Wildfire related expenditures have doubled from $\$ 730$ million to $\$ 1.4$ billion from 1998 to 2010 (NASF 2010, 2012). Funding support to the states comes predominantly from the state $(62 \%$ in 2008) and forestbased revenues $(21 \%$ in 2008$)$ with the federal government contributing roughly $10 \%$ (NASF 2010). There is no way to account for the total spent by local governments (Gorte 2013).
Federal agencies provide support to states and localities through programs, including State Fire Assistance (SFA), Volunteer Fire Assistance (VFA), and Fire Management Assistance Grant (FMAG), and by providing fire suppression personnel funding and equipment, if assistance is requested. Costs to states and localities are expected to rise over time as policy is moving in this direction as witnessed by the Cohesive Policy (2009) and other stated policy documents such as the QFR (USFS, USDOI BLM, NPS, BIA, and NASF 2009).

Acres moving toward desired class conditions are trending downward while hazardous fuel reduction in the WUI is increasing, as are the number of stewardship contract agreements. However, the pace is below what is needed to make positive net gains, given the total acreages in need of attention, which does not remain static in the face of changing budgetary conditions and priorities (Gorte and Bracmort 2012). Evaluations of fuel treatments and hazardous fuel reduction indicate that under some conditions they are effective in changing fire behavior, including reducing fire severity and tree mortality (USFS 2012b, $c$, Waltz et al. 2014). Investing in fuel treatments can avoid costs associated with large-scale fire. One study has indicated a cost avoided ratio of \$9-10/acre for investments in hazardous fuel treatment once the full costs of the wildfire are taken into account (Waltz et al. 2014).

\section{Wildfire governance}

The current wildfire governance system is highly fragmented. The governance system is an amalgamation of a variety of formal and informal policy directives, programs, budgets, and practices at the national, state, and local levels that seeks to restore fire adapted ecosystems, build fire adapted communities, and respond appropriately to wildfire. It is a federated system of governance in which federal agencies (USDA-USFS, USDOI-BLM, Park Service, BIA, FWS, and DOD) often work with state counterparts, counties, and municipalities through funding, policy directives, practices, and partnerships (Fleming et al. 2015). It is impractical to focus on all aspects and so the subsequent analysis hones in on the key areas that should be prioritized.

The previous analysis indicated that the key drivers in the wildfire social-ecological system are climate change, funding priorities that favor suppression activities over prevention and preparedness activities, and a need to protect structures and other values at risk in the WUI. These drivers are found in the exogenous and slow variable categories. It is not apparent that existing policies adequately match the challenges at the appropriate socialecological level, or if they do, they have not become institutionalized to effect change. More effective global and U.S.based climate policy could mitigate the effect of projected extreme fire behavior. The Kyoto Protocol has been in place since 1997, but has yet to become effectively implemented. Nonetheless, the globe is committed to a certain amount of temperature increase due to existing greenhouse gas (GHG) loading in the atmosphere (IPCC 2014a), and if more effective policy change were to come, it would be realized slowly. In the interim, focusing on reshaping federal budgetary priorities and the WUI are the more effective medium-term policy alternatives. Arguably, existing federal policy subsidizes the risk of building in the WUI, by protecting houses through suppression response and reducing fuels/or creating appropriate class conditions in land adjacent to the WUI 
(Gude et al. 2013). Until the incentives for building in the wildland urban interface are addressed, it is unlikely that the funding challenges that favor suppression over prevention and preparedness will shift.

\section{Climate change policy}

Projections for global policy to mitigate climate change, the most significant driver in the wildfire social-ecological system, are pessimistic. Climate change is a global scale problem and therefore necessitates a response on the same scale. The UN Framework Convention on Climate Change (UN FCCC), established in 1992, is the international treaty that seeks to address climate change. In 1995, countries participating in the convention realized that the initial reductions proposed in 1992 would be inadequate and in 1997 developed and adopted the Kyoto Protocol, which is now part of the FCCC. The Kyoto Protocol set emission reduction targets of $4.2 \%$ below the base year of 1990 to be met for 2008-2012 for industrialized countries (Olivier et al. 2014). The U.S. did not ratify the UN FCCC or Kyoto Protocol and Canada withdrew from the Kyoto Protocol in 2012. Beyond these exclusions, 197 countries have ratified the FCCC (UN FCCC 2015). Global carbon dioxide emissions continued to grow and in 2013 increased to a new record, albeit at slower growth rate than in previous years (Olivier et al. 2014). Recent increases in emissions are being driven by emerging economies with a decoupling of global economic growth rates from emission trends in industrialized countries (Olivier et al. 2014). China, the U.S., and European Union (EU) are the top global emitters. China's carbon emissions are growing at a slower rate than the past decade. In 2013, U.S. carbon emissions grew for the first time since the onset of the 2008 recession (Olivier et al. 2014). The EU has shown consistent decreases in its emissions since 2006 (Olivier et al. 2014).

U.S. Congressional opposition to climate change action has prevailed. However, in 2009 President Barack Obama committed to reduce carbon dioxide levels $17 \%$ below 2005 levels by 2020 , $42 \%$ below 2005 levels by 2030, and $83 \%$ below 2005 levels by 2050 (Executive Office of the President 2013). The U.S. has primarily used the Clean Air Act to address GHG reduction. In 2009, GHGs were identified by the U.S. Environmental Protection Agency to be a threat to public health and welfare, and GHG thresholds were set in 2010 as part of the Prevention of Significant Deterioration standards under the Clean Air Act (US EPA 2015a). These thresholds affect the largest, point source emitters: power plants, refineries, and cement production facilities (US EPA 2015a). A subsequent rule that affected cars took effect in 2011 (US EPA 2015a). Power plants are the largest single source of carbon emission in the U.S. In 2013, standards were established for new power plants and in 2014 standards were set for existing power plants. These standards have been finalized for light duty vehicles and will apply to model years 2017-2025. Renewable Fuel Standard (RFS) regulations were developed to reduce GHG emissions from renewable fuels and compliance deadlines were set in late 2014 (US EPA 2015a). As of 2013, carbon dioxide levels were reduced $8.5 \%$ below 2005 levels, mostly because of the economic recession, the replacement of coal-based power generation with natural gas, increases in wind and solar power generation, and increased energy efficiencies (US EPA 2015b). However, since 1990, GHG emissions in the U.S. have increased on average by $0.3 \%$ per year for a total of $7 \%$ since 2009 (US EPA 2015b). U.S. GHG emissions are projected to continue to grow at a slow rate. The impact of U.S. GHG emissions is unlikely to have a significant global impact in the face of growing emission from China and India. Projected trends for GHG intensification and hence continued increases in temperature and wildfire impacts will likely not abate in the new or distant future.

Federal wildfire policy

The 1995 Federal Wildland Fire Management Policy (USDA and USDOI 1995) and the Federal Fire Policy Review and Update of the 1995 Federal Wildland Fire Management Policy 2001 (USDA and USDOI 2001) lays out clear policy goals that can be used to address the challenge in the WUI and include (1) reaffirming that protection of life as the first priority, (2) recognizing wildland fire as a critical natural process, (3) requiring fire management plans be developed for all burnable acres, (4) requiring fire management decisions be consistent with approved land and resource management plans, and (5) clarifying the role of federal agencies in the wildland urban interface. However, implementation remains incomplete. The Wildland Fire Leadership Council (WFLC) is an intergovernmental committee that supports and provides oversight of the Federal Fire Management Policy. The National Fire Plan (USDA USDOI 2000b) and subsequent Western Governors' Association (WGA) 10-Year Comprehensive Strategy (WGA 2001) and Implementation Strategy (WGA 2002) identified four goals including the following: improving fire prevention and suppression, reducing hazardous fuels, restoring fire adapted ecosystems, and promoting community assistance, which entails creating economic incentives and industries to reduce fuels and restore ecosystems while also building social capacity to reduce the risk of wildfire and build collaboration among communities and all levels of government (WGA 2001, 2002). These documents move toward addressing the complex mix of interacting processes that will need to be addressed to reframe the shift from a predominant suppression focus to a prevention and preparedness focus (Steelman and Burke 2007).

The Healthy Forests Initiative 2002 (HFI) and Healthy Forests Restoration Act (HFRA) 2003 were passed with the intention to expedite the reduction of hazardous fuels on public lands (Vaughn and Cortner 2005, Steelman and DuMond 2009). The HFI entailed administrative reforms to the National Environmental Policy Act (NEPA) and the Endangered Species Act (ESA) to streamline and prioritize hazardous fuel reduction projects (USFS 2002). HFRA codified the NEPA and ESA reforms and authorized funding for projects and activities that implemented the 10-Year Strategy and the Implementation Plan including the use of stewardship contracts to meet the objectives of the Healthy Forest Initiative. HFRA allows the Forest Service and Bureau of Land Management (BLM) to prioritize areas for fuel reduction projects in the WUI. Although this helps protect communities in the WUI, it does not stem the growing number of structures in the WUI. The law recommends that half of the $\$ 760$ million in annual funding be directed to the WUI.

Recognizing that a more regional and local approach was needed to restore fire adapted ecosystems, build fire adapted communities, and respond appropriately to wildfire, the National Cohesive Wildland Fire Management Strategy (Cohesive Strategy) became the effective policy for interagency wildfire management in 2009 as part of the Federal Land Assistance, 
Management and Enhancement (FLAME) Act. The Cohesive Strategy supplants previous policy and aims to take the discussion of how to deal with the localized challenges of the WUI and wildfire problem to the states and municipalities.

In 2009, the FLAME Act (H.R. 5541) was passed to address the wildfire funding challenge. FLAME was intended to provide supplemental funding so that fire borrowing could be avoided. However, it was never fully funded by Congress and fire borrowing has continued. In 2014, the Obama Administration proposed the Wildfire Disaster Funding Act, to address this problem. This would allow the largest wildfires to be treated as natural disasters and funding from the Federal Emergency Management Agency would be made available for these fires. Previous attempts to address the problem of fire borrowing, namely the FLAME Act of 2009 have been inadequately implemented to remedy the problem. The Wildfire Disaster Funding Act of 2014, aimed at making FEMA funding available for the largest and most destructive wildfires, also failed to pass in Congress. The likelihood of passage in the 114th Congress is unlikely because of change in committee leadership and composition.

\section{State and local policies}

All states have forestry agencies, departments, or divisions. State forestry agencies have broad responsibilities including wildfire. States are responsible for wildfire management on state and private lands. State Fire Assistance (SFA) and Volunteer Fire Assistance (VFA) are the primary programs that states and local fire departments use to develop preparedness and response capabilities for wildland fire management. SFA provides technical and financial assistance to enhance firefighting capacity, carry out wildfire hazard mitigation projects, and facilitate FIREWISE workshops. VFA provides funding for volunteer fire departments to improve communication capabilities, increase wildland fire management training and purchase firefighting clothing and equipment.

Community Wildfire Protection Plans (CWPPs), which are created at the community level to establish priorities for wildfire risk mitigation, were created under HFRA 2002. Federal funding to assist fuel reduction on private lands can come through SFA and VFA. By the end of 2009, state forestry agencies had assisted with the completion of 5567 CWPPPs (NASF 2010).

Disaster assistance can also come from the Federal Emergency Management Agency (FEMA) in the form of Fire Management Assistance Grants (FMAG) to help cover firefighting costs when a state declares a major disaster. FMAG can cover up to $75 \%$ of the costs for a locality if costs reach a threshold established annually by FEMA. If the President declares a disaster, then the Robert T. Stafford Disaster Relief and Emergency Assistance Act can provide assistance.

Community-based efforts such as Firewise and Fire Adapted Communities depend on local residents to take an active role in efforts to address wildfire risk. These programs seek to create a shared sense of responsibility for prefire mitigation in the WUI. Fire Adapted Communities (http://www.fireadapted.org/) is funded at $\$ 2.6$ million/year by the USFS. Firewise is funded at roughly $\$ 1$ million per year from federal and National Fire Protection Association (NFPA) sources (M. Steinberg, Director, National Fire Prevention Agency and Firewise, 2015, personal communication). Both programs rely on local communities to conduct risk assessments based on local ecological characteristics and fire history to create mitigation plans. They also encourage resident support of land management agencies by learning about wildfire risk reduction efforts, such as using prescribed fire to manage local landscapes.

Emergency assistance is also available for agricultural land rehabilitation post fire. Within the U.S. Department of Agriculture, the Natural Resources Conservation Service administers the Emergency Watershed Protection Program and the Farm Service Agency administers the Emergency Conservation Program (Hoover 2015).

Development of the WUI is a state and local responsibility, not a federal responsibility. Local governments are typically responsible for structural fire on private property. Zoning codes, building codes, construction standards related to building on private property in the WUI are regulated locally. The insurance industry and home fire insurance, which provide risk management tools for building in the WUI, are regulated by state agencies.

\section{GOVERNANCE EFFECTIVENESS}

Linkages in the social-ecological system

I began with two research questions:

To what extent do the spatial and temporal scales of in our wildfire governance system fit the social-ecological dynamics that drive the system?

The answer is not well. Fast variables dictate the policy response to the detriment of addressing slow variables and exogenous controls. Development in the WUI means there are increased values at risk, which historically has necessitated a federal and/or state response to protect these values. Driving development in the WUI are constitutionally protected private property rights, weak or absent zoning, planning or regulation of WUI development, and an inactive insurance industry. Because the values and risks are so great in the WUI, media and political attention tends to drive policy response in these immediate areas. However, climate change and regional climate patterns are driving observable ecological trends. Carbon dioxide (and other GHGs) are driving temperature, which is driving changing wildfire behavior, landscape level vegetative change, and snow melt hydrology. Changing fire behavior threatens more houses in the WUI, which results in greater emphasis on suppression response at the expense of prevention efforts to mitigate risks in the WUI (Calkin et al. 2015, Fischer et al. 2016).

What could we do to improve wildfire governance if we were to embrace social-ecological dynamics?

Our goals should be an anticipatory wildfire governance system that can facilitate more ecologically resilient landscapes and socially resilient communities. We need policies and practices that are better aligned with the social and ecological realities in the places where we expect wildfire to continue to be a problem. An integrated framework for action is needed at the global, national, and local levels. Although action at the local level is essential, this action needs to be informed by the drivers at the other scales. Mutually reinforcing policy at the local, state, federal levels and beyond will be important to create consistent incentives for action. Effective responses will need to be adaptive, emergent, and holistic 
while also acknowledging that they are nested within higher order temporal and spatial processes that impact their effectiveness. To facilitate this kind of transformative governance change, we will need to see strong commitment to the most critical cross-scale dynamics including an effective climate change policy, a radical reprioritization of resources to the state and local levels, redirection of federal and state incentives to reduce building in WUI and the use of federal level resources only in the most extreme wildfires.

Key elements of a future strategy would include the following characteristics operating at all scales of governance:

1. Do not take historical patterns as givens. Conservation expectations are traditionally geared to restore to historical patterns (Swetnam et al. 1999), but changes in climate that drive changes in species composition and structure mean that these norms may no longer be climatologically appropriate (Millar et al. 2007). In this era of a nonanalogous past, it is important to redefine what it means to be "resilient." Forecasting based on past trends will be of limited use in a future that will see greater variation in system responses (Milly et al. 2008). This will entail building capacity for what Wiek et al. (2011) have labeled anticipatory competency. This means the ability to adapt strategies iteratively based on new information/knowledge to alter path dependent trajectories toward a more sustainable future state, including foresight, engagement, and integration (Guston 2014). For wildfire this might entail multiple scenarios based on climate change models, downscaling, and local knowledge. It means avoiding single scenario options (Quay 2010). Heightened uncertainty means multiple scenarios need to be considered.

2. Identify future social and ecological thresholds of concern. These thresholds would trigger actions to maintain the system in a current state or prepare it for what the next state might be. This will require the need to establish trigger points or signals that would stimulate action when thresholds have been met and new or different responses are needed. In the context of wildfire, it could be recognizing when specific kinds of values at risk, both social and ecological, have been affected. For instance, the recent wildfires in Tasmania in 2015 and the 2016 fires in Fort McMurray, Alberta perhaps signal that key ecological and human community thresholds have been crossed. These signals necessitate broad discussion and consideration of transformational new approaches for how human and ecological can coexist with wildfire. Alternatively, signals such as the failure of conventional tools to predict adequately fire behavior could trigger reflection and the need take contingent action.

3. Embrace diversity/heterogeneity as principles in ecological and social responses. The "diversity hypothesis" suggests that complex problems must be governed by equally complex systems (Duit et al. 2010). Because the wildfire problem occurs on multiple temporal and spatial scales, it is important to acknowledge that we need a governance system that can match that complexity. Although we have elements of policy and institutional diversity woven into the governance system, it is unclear how polices and institutions affect each other at different levels, create feedbacks and cascades. Efforts to model these systems from the local to the global to better understand how they interconnect could contribute to enhanced learning among and between levels. Additionally, gaps in governance could be better identified if we had more comprehensive maps of where action is currently taking place. Heterogeneity is also emerging as strategy for ecosystem resilience (Moritz et al. 2014). Diversity across vegetative type, stand structures, and successional age classes as well as patch mosaic burning has been advocated for biodiversity conservation (Moritz et al. 2014).

4. Create learning among different scales of actors throughout the governance system. People ultimately drive the policies and institutions within the governance systems. To support the governance complexity necessary to match the problem, actors need to network and learn from each other. Scaffolding that helps connection between and among levels can facilitate individual and systems level learning. To facilitate this learning, skills in interpersonal competence and systems thinking need to be cultivated (Wiek et al. 2011). This would include the ability to develop, maintain and shepherd collaborative social processes at appropriate scales to implement select strategies to incorporate key perspectives in successive rounds of problem definition and alternative selection.

There are many different approaches to systems thinking. In this article I chose to pursue the one laid out by Chapin et al. (2006) and further used by Meek (2011) because of its applicability to social-ecological systems thinking in a complex, multilevel system with multiple organizations and managerial participants. There are many other frameworks, approaches, and tools that facilitate insight into systems and their complexity (e.g., Senge and Sherman 1992, Jackson 2003, Meadows and Wright 2008) that likely would produce different insights. The Chapin (2006) and Meek (2011) approach was valuable in the wildfire context because of its ability to portray the system from an ecological, social, and institutional standpoint, the multiple relevant scales and the focus on multiple organizational and/or agency influences. Further comparative research with different frameworks is an area for future work.

\section{CONCLUSIONS}

A key question at this time is the counterfactual. What happens if we do not make changes in how we address the temporal and spatial disconnects in the current wildfire governance system? This analysis suggests that we would continue to react to the fast social variables and perpetuate the existing problems. Outcomes can be anticipated: more carbon in the atmosphere, higher temperatures, less snow, lower humidity, more extreme fire, changing landscapes, more values at risk, more property destroyed, more fire fighters at risk, and more reactive spending.

There are no easy solutions to the current wildfire problem. Reframing the problem as a social-ecological one helps identify the critical cross-scale dynamics that are currently not a part of much of the wildfire discussion. We need governance that can take into account the complex social and biophysical dimensions of the entire system. More complete knowledge about how this social-ecological system matches our current policy and institutional response can lead to more sustainable, long-term 
alternatives to the wildfire problem. Design principles, rather than concrete policy recipes, can guide thinking about how we approach this more effective governance system.

Responses to this article can be read online at: http://www.ecologyandsociety.org/issues/responses. $\mathrm{php} / 8681$

\section{Acknowledgments:}

I would like to thank Dr. Cass Moseley who has been a valued colleague and stimulated my thinking through our helpful discussion on these topics for many years.

\section{LITERATURE CITED}

Allen, C. G., M. Savage, D. A. Falk, K. F. Suckling, T. W. Swetnam, T. Schulke, P. B. Stacey, P. Morgan, M. Hoffman, and J. T. Klingel. 2002. Ecological restoration of southwestern Ponderosa Pine ecosystem: a broad perspective. Ecological Applications 12(5):1418-1433. http://dx.doi.org/10.1890/1051-0761 (2002)012[1418:erospp]2.0.co;2

Attiwill, P., and D. Binkley. 2013. Exploring the mega-fire reality: a 'forest ecology and management' conference. Forest Ecology and Management 294:1-3. http://dx.doi.org/10.1016/j.foreco.2012.12.025

Botts, H., J. Thomas, S. Kolk, S. McCabe, B. Stueck, and L. Suhr. 2013. CoreLogic wildfire hazard risk report: residential wildfire exposure estimates for the western United States. CoreLogic, Irvine, California, USA. [online] URL: http://www.corelogic. com/research/wildfire-risk-report/2013-wildfire-hazard-risk-report. pdf

Bracmort, K. 2013. Wildfire management: federal funding and related statistics. Report $\mathrm{R} 43077$. Congressional Research Service, Washington, D.C., USA.

Brown, T. J., B. L. Hall, and A. L. Westerling. 2004. The impact of twenty-first century climate change on wildland fire danger in the western United States: an application perspective. Climate Change 62:365-388. http://dx.doi.org/10.1023/B:CLIM.0000013680.07783. $\underline{\text { de }}$

Calkin, D. E., M. P. Thompson, and M. A. Finney. 2015. Negative consequences of positive feedbacks in US wildfire management. Forest Ecosystems 2:1-10. http://dx.doi.org/10.1186/s40663-015-0033-8

Cash, D. W., W. N. Adger, F. Berkes, P. Garden, L. Lebel, P. Olsson, and O. Young. 2006. Scale and cross-scale dynamics: governance and information in a multilevel world. Ecology and Society 11 (2):8. [online] URL: http://www.ecologyandsociety.org/vol11/ iss $2 / \operatorname{art} 8 /$

Chapin, F. S., III, A. L. Lovecraft, E. S. Zavaleta, J. Nelson, M. D. Robards, G. P. Kofinas, S. F/ Trainor, G. D. Peterson, H. P. Huntington, and R. L. Naylor. 2006. Policy strategies to address sustainability of Alaskan boreal forests in response to a directionally changing climate. Proceedings of the National Academy of Sciences 103(45):16637-16643. http://dx.doi. org/10.1073/pnas.0606955103
Dombeck, M. P., J. E. Williams, and C. A. Wood. 2004. Wildfire policy and public lands: integrating scientific understanding with social concerns across landscapes. Conservation Biology 18 (4):883-889. http://dx.doi.org/10.1111/j.1523-1739.2004.00491.x

Duit, A., and V. Galaz. 2008. Governance and complexityemerging issues for governance theory. Governance 21:311-335. http://dx.doi.org/10.1111/j.1468-0491.2008.00402.x

Duit, A., V. Galaz, K. Eckerberg, and J. Ebbesson. 2010. Governance, complexity, and resilience. Global Environmental Change 20(3):363-368. http://dx.doi.org/10.1016/j.gloenvcha.2010.04.006

Executive Office of the President. 2013. The president's climate action plan. Executive Office of the President, Washington, D.C., USA. [online] URL: https://www.whitehouse.gov/sites/default/ files/image/president27sclimateactionplan.pdf

Ferrier, G. 1995. Let the people judge: wise use and the private property rights movement. Island Press, Washington, D.C., USA.

Fischer, A. P., T. A. Spies, T. A. Steelman, C. Moseley, B. R. Johnson, J. D. Bailey, A. A. Ager, P. Bourgeron, S. Charnley, B. M. Collins, J. D. Kline, J. E. Leahy, J. S. Littell, J. D. A. Millington, M. Nielsen-Pincus, C. S. Olsen, T. B. Paveglio, C. I. Roos, M. M. Steen-Adams, F. R. Stevens, J. Vukomanovic, E. M. White, and D. M. J. S. Bowman. 2016. Wildfire risk as a socioecological pathology. Frontiers in Ecology and the Environment 14 (5):276-284. http://dx.doi.org/10.1002/fee.1283

Flannigan, M., A. S. Cantin, W. J. de Groot, M. Wotton, A. Newbery, and L. M. Gowman. 2013. Global wildland fire season severity in the 21 st century. Forest Ecology and Management 294:54-61. http://dx.doi.org/10.1016/i.foreco.2012.10.022

Flannigan, M. D., M. A. Krawchuk, W. J. de Groot, B. M. Wotton, and L. M. Gowman. 2009. Implications of changing climate for global wildland fire. International Journal of Wildland Fire 18 (5):483-507. http://dx.doi.org/10.1071/wf08187

Fleming, C. J., E. B. McCartha, and T. A. Steelman. 2015. Conflict and collaboration in wildfire management: the role of mission alignment. Public Administration Review 75(3):445-454. http://dx. doi.org/10.1111/puar.12353

Folke, C., L. Pritchard, Jr., F. Berkes, J. Colding, and U. Svedin. 2007. The problem of fit between ecosystems and institutions: ten years later. Ecology and Society 12(1):30. [online] URL: http:// www.ecologyandsociety.org/vol12/iss1/art30

Gerlak, A. K. 2014. Policy interactions in human-landscape systems. Environmental Management 53(1):67-75. http://dx.doi. org/10.1007/s00267-013-0068-y

Gorte, R. W. 2011. Federal funding for wildfire control and management. Congressional Research Service, U.S. Congress, Washington, D.C., USA. [online] URL: http://www.fas.org/sgp/ crs/misc/RL33990.pdf

Gorte, R. 2013. The rising cost of wildfire protection. Headwaters Economics, Bozeman, Montana, USA. [online] URL: http:// headwaterseconomics.org/wphw/wp-content/uploads/fire-costsbackground-report.pdf

Gorte, R. W., and K. Bracmort. 2012. Forest fire/wildfire protection. Congressional Research Service, U.S. Congress, 
Washington, D.C., USA. [online] URL: http://www.fas.org/sgp/ crs/misc/RL30755.pdf

Gude, P. H., K. Jones, R. Rasker, and M. C. Greenwood. 2013. Evidence for the effect of homes on wildfire suppression costs. International Journal of Wildland Fire 22:537-548. http://dx.doi. org/10.1071/WF11095

Gude, P., R. Rasker, and J. Van den Noort. 2008. Potential for future development on fire-prone lands. Journal of Forestry 106 (4):198-205.

Gunderson, L. H., C. S. Holling, and S. S. Light. 1995. Barriers and bridges to the renewal of ecosystems and institutions. Columbia University Press, New York, New York, USA.

Guston, D. H. 2014. Understanding 'anticipatory governance.' Social Studies of Science 44(2):218-242. http://dx.doi. org/10.1177/0306312713508669

Hoover, K. 2015. Federal assistance for wildfire response and recovery. Congressional Research Service, U.S. Congress, Washington, D.C., USA. [online] URL: http://nationalaglawcenter. org/wp-content/uploads/assets/crs/R41858.pdf

Intergovernmental Panel on Climate Change (IPCC). $2014 b$. Climate change 2014: impacts, adaptation, and vulnerability. Part A: global and sectoral aspects. Contribution of Working Group II to the Fifth Assessment Report of the Intergovernmental Panel on Climate Change. C. B. Field, V. R. Barros, D. J. Dokken, K. J. Mach, M. D. Mastrandrea, T. E. Bilir, M. Chatterjee, K. L. Ebi, Y. O. Estrada, R. C. Genova, B. Girma, E. S. Kissel, A. N. Levy, S. MacCracken, P. R. Mastrandrea, and L. L. White, editors. Cambridge University Press, Cambridge, UK.

Intergovernmental Panel on Climate Change (IPCC). 2014a. Climate change 2014: synthesis report. Contribution of Working Groups I, II and III to the Fifth Assessment Report of the Intergovernmental Panel on Climate Change. R. K. Pachauri and L. A. Meyer, editors. IPCC, Geneva, Switzerland.

International Code Council. 2008. The Blue Ribbon Panel Report on wildland urban interface fire. International Code Council, Wasington, D.C., USA. [online] URL: http://www.iawfonline. org/NWUI/BlueRibbonReport-Low.pdf

Jackson, M. C. 2003. Systems thinking: creative holism for managers. Wiley, Chichester, UK.

Kauffman, J. B. 2004. Death rides the forest: perceptions of fire, land use, and ecological restoration of western forests. Conservation Biology 18(4):878-882 http://dx.doi.org/10.1111/ j.1523-1739.2004.545_1.x

Liu, J., T. Dietz, S. R. Carpenter, C. Folke, M. Alberti, C. L. Redman, S. H. Schneider, E. Ostrom, A. N. Pell, J. Lubchenco, W. W. Taylor, Z. Ouyang, P. Deadman, T. Kratz, and W. Provencher. 2007. Coupled human and natural systems. AMBIO 36(8):639-649. http://dx.doi.org/10.1579/0044-7447(2007)36[639: chans] 2.0.co;2

Liu, Y., S. L. Goodrick, and J. A. Stanturf. 2013. Future U.S. wildfire potential trends projected using a dynamically downscaled climate change scenario. Forest Ecology and Management 294:120-135. http://dx.doi.org/10.1016/j.foreco.2012.06.049
McCright, A. M., and R. E. Dunlap. 2011. The politicization of climate change and polarization in the American public's views of global warming, 2001-2010. Sociological Quarterly 52 (2):155-194. http://dx.doi.org/10.1111/j.1533-8525.2011.01198.x

McKenzie, D. Z. Gedalof, D. L. Peterson, and P. Mote. 2004. Climate change, wildfire, and conservation. Conservation Biology 18(4):890-902. http://dx.doi.org/10.1111/j.1523-1739.2004.00492. $\underline{x}$

Meadows, D. H. and D. Wright. 2008. Thinking in systems: a primer. Chelsea Green, White River Junction, Vermont, USA.

Meek, C. L. 2011. Putting the US polar bear debate into context: the disconnect between old policy and new problems. Marine Policy 35(4):430-439. http://dx.doi.org/10.1016/j.marpol.2010.11.005

Millar, C. I., N. L. Stephenson, and S. L. Stephens. 2007. Climate change and forests of the future: managing in the face of uncertainty. Ecological applications 17(8):2145-2151. http://dx. doi.org/10.1890/06-1715.1

Milly, P. C. D., J. Betancourt, M. Falkenmark, R. M. Hirsch, Z. W. Kundzewicz, D. P. Lettenmaier, and R. J. Stouffer. 2008. Stationarity is dead: Whither water management? Science 319 (5863):573-574. http://dx.doi.org/10.1126/science.1151915

Moreira, F., O. Viedma, M. Arianoutsou, T. Curt, N. Koutsias, E. Rigolot, A. Barbati, P. Corona, P. Vaz, G. Xanthopoulos, F. Mouillot, and E. Bilgili. 2011. Landscape-wildfire interactions in southern Europe: implications for landscape management. Journal of Environmental Management 92(10):2389-2402. http:// dx.doi.org/10.1016/j.jenvman.2011.06.028

Moriondo, M., P. Good, R. Durao, M. Bindi, C. Giannakopoulos, and J. Corte-Real. 2006. Potential impact of climate change on fire risk in the Mediterranean area. Climate Research 31(1):85-95. http://dx.doi.org/10.3354/cr031085

Moritz, M. A., E. Batllori, R. A. Bradstock, A. M. Gill, J. Handmer, P. F. Hessburg, J. Leonard, S. McCaffrey, D. C. Odion, T. Schoennagel, and A. D Syphard. 2014. Learning to coexist with wildfire. Nature 515(7525):58-66. http://dx.doi.org/10.1038/ $\underline{\text { nature } 13946}$

Moritz, M. A., M. A. Parisien, E. Batllori, M. A. Krawchuk, J. Van Dorn, D. J. Ganz, and K. Hayhoe. 2012. Climate change and disruptions to global fire activity. Ecosphere 3(6):49. http://dx.doi. org/10.1890/es11-00345.1

National Association of Home Builders. 2014. Housing economics. National Association of Home Builders, Washington, D.C., USA. [online] URL: http://www.nahb.org/en/research/ housing-economics.aspx

National Association of State Foresters (NASF). 2010. State foresters by the numbers: data and analysis from the 2008 NASF State Forestry Statistics Survey. NASF, Washington, D.C., USA. [online] URL: http://www.stateforesters.org/sites/default/files/ files/NASF-2008-Statistics-Report-1.pdf

National Association of State Foresters (NASF). 2012. State foresters by the numbers: data and analysis from the 2010 NASF State Forestry Statistics Survey. NASF, Washington, D.C., USA. 
[online] URL: http://www.stateforesters.org/sites/default/files/ publication-documents/State $\% 20$ Foresters $\% 20$ by $\% 20$ the $\% 20$ Numbers $\%$ 20Final.pdf

National Interagency Fire Center (NIFC). 2014. Total wildland fires and acres (1960-2015). NIFC, Boise, Idaho, USA. [online] URL: https://www.nifc.gov/fireInfo/fireInfo stats totalFires.html

National Wildfire Coordinating Group (NWCG). 2014. RMC safety gram archive. NWCG, Boise, Idaho, USA. [online] URL: http://www.nwcg.gov/committees/risk-management-committee/resources/ $\underline{\text { rmc-safety-gram-archive }}$

Nisbet, E. C., P. S. Hart, T. Myers, and M. Ellithorpe. 2013. Attitude change in competitive framing environments? Open-/ closed-mindedness, framing effects, and climate change. Journal of Communication 63(4):766-785. http://dx.doi.org/10.1111/ jcom. 12040

Noss, R. F., J. F. Franklin, W. L. Baker, T. Schoennagel, and P. B. Moyle. 2006. Managing fire-prone forests in the western United States. Frontiers in Ecological Environments 4(9):481-487. http:// dx.doi.org/10.1890/1540-9295(2006)4[481:mffitw]2.0.co;2

Olivier J. G. J., G. Janssens-Maenhout, M. Muntean, and J. A. H. W. Peters. 2014. Trends in global CO2 emissions: 2014 Report. PBL Netherlands Environmental Assessment Agency, The Hague, Netherlands, and Joint Research Centre, European Commission, Brussels, Belgium.

Olsson, P., C. Folke, V. Galaz, T. Hahn, and L. Schultz. 2007. Enhancing the fit through adaptive co-management: creating and maintaining bridging functions for matching scales in the Kristianstads Vattenrike Biosphere Reserve Sweden. Ecology and Society 12(1):28. [online] URL: http://www.ecologyandsociety. org/vol12/iss1/art28/

Pyne, S. J. 1997. World fire: the culture of fire on Earth. University of Washington Press, Seattle, Washington, USA.

Quay, R. 2010. Anticipatory governance: a tool for climate change adaptation. Journal of the American Planning Association 76 (4):496-511. http://dx.doi.org/10.1080/01944363.2010.508428

Reinhardt, E. D., R. E. Keane, D. E. Calkin, and J. D. Cohen. 2008. Objectives and considerations for wildland fuel treatment in forested ecosystems of the interior western United States. Forest Ecology and Management 256(12):1997-2006. http://dx.doi. org/10.1016/j.foreco.2008.09.016

Rocky Mountain Insurance Information Association. 2012. Catastrophe facts and statistics. Rocky Mountain Insurance Information Association, Greenwood Village, Colorado, USA. [online] URL: http://www.rmiia.org/catastrophes and statistics/ catastrophes.asp

Running, S. W. 2006. Is global warming causing more, larger wildfires? Science 313:927-928. http://dx.doi.org/10.1126/ science. 1130370

Saveland, J. M., M. Stock, and D. A. Cleaves. 1988. Decisionmaking bias in wilderness fire management: implications for expert system development. AI Applications in Natural Resource Management (USA).

Schmidt, K. M., J. P. Menakis, C. C. Hardy, W. J. Hann, and D. L. Bunnell. 2002. Development of coarse-scale spatial data for wildland fire and fuel management. General Technical Report RMRS-GTR-87. U.S. Forest Service, Rocky Mountain Research Station, Fort Collins, Colorado, USA.

Schoennagel, T., T. T. Veblen, and W. H. Romme. 2004. The interaction of fire, fuels, and climate across Rocky Mountain Forests. BioSciences 54(7):661-676. http://dx.doi.org/10.1641/0006-3568 (2004)054[0661:tioffa]2.0.co:2

Senge, P. M., and J. D. Sterman. 1992. Systems thinking and organizational learning: acting locally and thinking globally in the organization of the future. European Journal of Operational Research 59(1):137-150. http://dx.doi.org/10.1016/0377-2217(92) 90011-W

Spies, T. A., E. M. White, J. D. Kline, A. P. Fischer, A. Ager, J. Bailey, J. Bolte, J. Koch, E. Platt, C. S. Olsen, D. Jacobs, B. Shindler, M. M. Steen-Adams, and R. Hammer. 2014. Examining fire-prone forest landscapes as coupled human and natural systems. Ecology and Society 19(3):9. http://dx.doi.org/10.5751/ ES-06584-190309

Steelman, T. A., and C. Burke. 2007. Is wildfire policy in the United States sustainable? Journal of Forestry 33:67. http://dx. doi.org/10.2139/ssrn.1931057

Steelman, T. A., and M. E. DuMond. 2009. Serving the common interest in U.S. forest policy: a case study of the Healthy Forests Restoration Act. Environmental Management 43(3):396-410. http://dx.doi.org/10.1007/s00267-008-9264-6

Stephens, S. L., J. K. Agee, P. Z. Fulé, M. P. North, W. H. Romme, T. W. Swetnam, and M. G. Turner. 2013. Managing forests and fire in changing climates. Science 342:41-42. http://dx.doi. org/10.1126/science. 1240294

Swetnam, T. W., C. D. Allen, and J. L. Betancourt. 1999. Applied historical ecology: using the past to manage for the future. Ecological Applications 9(4):1189-1206. http://dx.doi. org/10.1890/1051-0761(1999)009[1189:aheutp]2.0.co;2

Termeer, C. J. A. M., A. Dewulf, and M. Van Lieshout. 2010. Disentangling scale approaches in governance research: comparing monocentric, multilevel, and adaptive governance. Ecology and Society 15(4):29. [online] URL: http://www. ecologyandsociety.org/vol15/iss4/art29/

Underdal, A. 2008. Determining the causal significance of institutions: accomplishments and challenges. Pages 49-78 in O. R. Young, L. A. King, and H. Schroeder, editors. Institutions and environmental change: principal findings, applications, and research frontiers. The MIT Press, Cambridge, Massachusetts, USA. http://dx.doi.org/10.7551/mitpress/9780262240574.003.0002

U.N. Framework Convention on Climate Change (UN FCCC). 2015. Background on the UNFCCC: the international response to climate change. UN FCCC, Bonn, Germany. [online] URL: http:// unfccc.int/essential background/items/6031.php

U.S. Department of Agriculture, Office of Inspector General (USDA OIG). 2006. Audit report: forest service large fire suppression costs. Report no. 08601-44-SF. USDA OIG, Washington, D.C., USA. [online] URL: http://www.usda.gov/oig/ webdocs/08601-44-SF.pdf

U.S. Department of Agriculture and U.S. Department of the Interior (USDA and USDOI). 1995. Federal wildland fire 
management: policy \& program review. USDA and USDOI, Washington, D.C., USA. [online] URL: http://www.forestsandrangelands. gov/strategy/documents/foundational/1995 fed wildland fire $\mathrm{p}$ olicy program_report.pdf

U.S. Department of Agriculture and U.S. Department of the Interior (USDA and USDOI). 2000a. Managing the impact of wildfires on communities and the environment: a report to the President in response to the wildfires of 2000. USDA and USDOI, Washington, D.C., USA. [online] URL: http://www.forestsandrangelands. gov/resources/reports/documents/2001/8-20-en.pdf

U.S. Department of Agriculture and U.S. Department of the Interior (USDA and USDOI). 2000b. Previous wildland fire management initiatives: national fire plan. USDA and USDOI, Washington, D.C., USA. [online] URL: http://www.forestsandrangelands. gov/resources/overview/

U.S. Department of Agriculture and U.S. Department of the Interior (USDA and USDOI). 2001. Review and update of the 1995 federal wildland fire management policy. USDA and USDOI, Washington, D.C., USA. [online] URL: http://www.nifc.gov/ PIO bb/Policy/FederalWildlandFireManagementPolicy_2001.pdf

U.S. Department of Agriculture and U.S. Department of the Interior (USDA and USDOI). 2003. Interagency strategy for the implementation of federal wildland fire management policy. USDA and USDOI, Washington, D.C., USA. [online] URL: http://www. sierraforestlegacy.org/Resources/Community/SmokeManagement/ AirQualityPolicy/FedWldFireMgmtPolicy.pdf

U.S. Department of Agriculture and U.S. Department of the Interior (USDA and USDOI). 2006. Protecting people and natural resources: a cohesive fuels treatment strategy. USDA and USDOI, Washington, D.C., USA. [online] URL: http://www.forestsandrangelands. gov/resources/documents/CFTS 03-03-06.pdf

U.S. Department of Agriculture and U.S. Department of the Interior (USDA and USDOI). 2009a. Guidance for implementation of federal wildland fire management policy. USDA and USDOI, Washington, D.C., USA. [online] URL: https:// www.nifc.gov/policies/policies documents/GIFWFMP.pdf

U.S. Department of Agriculture and U.S. Department of the Interior (USDA and USDOI). 2009b. A national cohesive wildland fire management strategy. USDA and USDOI, Washington, D. C., USA. [online] URL: http://www.doi.gov/pmb/owf/ upload/1 CohesiveStrategy03172011.pdf

U.S. Environmental Protection Agency (US EPA). $2015 a$. Regulatory initiatives. US EPA, Washington, D.C., USA. [online] URL: http://www.epa.gov/climatechange/EPAactivities/regulatoryinitiatives.html

U.S. Environmental Protection Agency (US EPA). $2015 b$. Inventory of U.S. greenhouse gas emissions and sinks: 1990-2013. US EPA, Washington, D.C., USA. [online] URL: https://www. epa.gov/ghgemissions/inventory-us-greenhouse-gas-emissions-andsinks-1990-2013

U.S. Forest Service (USFS). 2002. Healthy forests initiative. U.S. Department of Agriculture, Washington, D.C., USA. [online] URL: http://www.forestsandrangelands.gov/resources/overview/

U.S. Forest Service (USFS). 2003a. Stewardship end result contracting projects. P.L. 108-7 (16 USC 2104 Note). U.S.
Department of Agriculture, Washington, D.C., USA. [online] URL: http://www.fs.fed.us/restoration/Stewardship_Contracting/16usc2104note.shtml

U.S. Forest Service (USFS). 2003b. Healthy Forests Restoration Act of 2003: summary of implementation actions. U.S. Department of Agriculture, Washington, D.C., USA. [online] URL: http:// www.forestsandrangelands.gov/resources/overview/hfraimplementation12-2004.shtml

U.S. Forest Service (USFS). 2009a. The Federal Land Assistance, Management and Enhancement Act of 2009 Report to Congress. U.S. Department of Agriculture, Washington, D.C., USA. [online] URL: http://www.fs.fed.us/sites/default/files/media/2014/25/ cr-2010-flameaof2009-ecm6751208.pdf

U.S. Forest Service (USFS). 2009b. Collaborative forest landscape restoration program overview. Omnibus Public Land Management Act of 2009: Title IV--Forest Landscape Restoration. U.S. Department of Agriculture, Washington, D.C., USA. [online] URL: http://www.fs.fed.us/restoration/CFLRP/overview.shtml

U.S. Forest Service (USFS). 2009c. Fiscal year 2010 President's budget: budget justification. U.S. Department of Agriculture, Washington, D.C., USA. [online] URL: http://www.fs.fed.us/ sites/default/files/fy2010-president-budget-request-justification.pdf

U.S. Forest Service (USFS). 2010. Fiscal year 2011 President's budget: budget justification. U.S. Department of Agriculture, Washington, D.C., USA. [online] URL: http://www.fs.fed.us/ sites/default/files/fy2011-forest-service-budget-justification.pdf

U.S. Forest Service (USFS). 2011. Fiscal year 2012 President's budget: budget justification. U.S. Department of Agriculture, Washington, D.C., USA. [online] URL: http://www.fs.fed.us/ aboutus/budget/2012/justification/FY2012-USDA-Forest-Servicebudget-justification.pdf

U.S. Forest Service (USFS). 2012a. Fiscal year 2013 President's budget: budget justification. U.S. Department of Agriculture, Washington, D.C., USA. [online] URL: http://www.fs.fed.us/ aboutus/budget/2013/fy2013-justification.pdf

U.S. Forest Service (USFS). 2012b. Increasing the pace of restoration and job creation on our national forests. U.S. Department of Agriculture, Washington, D.C., USA. [online] URL: http://www.fs.fed.us/sites/default/files/legacy files/media/ types/publication/field pdf/increasing-pace-restoration-job-creation-2012. pdf

U.S. Forest Service (USFS). 2012c. People restoring America's forests: 2012 report on the Collaborative Forest Landscape Restoration Program. U.S. Department of Agriculture, Washington, D.C., USA. [online] URL: http://www.fs.fed.us/ restoration/documents/cflrp/CoalitionReports/CFLRP2012AnnualReport20130108.pdf

U.S. Forest Service (USFS). 2013. Fiscal year 2014 budget justification. U.S. Department of Agriculture, Washington, D.C., USA. [online] URL: http://www.fs.fed.us/aboutus/budget/2014/ FY2014ForestServiceBudgetJustificationFina1041613.pdf

U.S. Forest Service (USFS). 2014. Fiscal year 2015 budget justification. U.S. Department of Agriculture, Washington, D.C., USA. [online] URL: http://www.fs.fed.us/aboutus/budget/2015/ FS15-FS-Budget-Justification.pdf 
U.S. Forest Service (USFS). 2015. Fiscal year 2016 budget justification. U.S. Department of Agriculture, Washington, D.C., USA. [online] URL: http://www.fs.fed.us/sites/default/files/ media/2015/07/fy2016-budgetjustification-update-four.pdf

U.S. Forest Service, U.S. Department of the Interior, Bureau of Land Management, National Park Service, Bureau of Indian Affairs, and National Association of State Foresters (USFS, USDOI BLM, NPS, BIA, and NASF). 2005. Quadrennial fire and fuel review report. Washington, D.C., USA. [online] URL: http:// www.forestsandrangelands.gov/strategy/documents/foundational/ qffr final report 20050719.pdf

U.S. Forest Service, U.S. Department of the Interior, Bureau of Land Management, National Park Service, Bureau of Indian Affairs, and National Association of State Foresters (USFS, USDOI BLM, NPS, BIA, and NASF). 2009. Quadrennial fire review. Washington, D.C., USA. [online] URL: https://www.iafc. org/files/wild_QFR2009Report.pdf

U.S. Government Accountability Office (US GAO). 2009. Wildland fire management. GAO-09-877. U.S. Government Accountability Office, Washington, D.C., USA.

Vaughn, J., and H. Cortner. 2005. George W. Bush's healthy forests. University Press of Colorado, Boulder, Colorado, USA.

Victor, D. 2004. The collapse of the Kyoto Protocol and the struggle to slow global warming. Princeton University Press, Princeton, New Jersey, USA. http://dx.doi.org/10.1515/9781400824069

Waltz, A. E. M., M. T. Stoddard, E. L. Kalies, J. D. Springer, D. W. Huffman, and A. S. Meador. 2014. Effectiveness of fuel reduction treatments: assessing metrics of forest resiliency and wildfire severity after the Wallow Fire, AZ. Forest Ecology and Management 334:43-52. http://dx.doi.org/10.1016/j.foreco.2014.08.026

Westerling, A. L., H. G. Hidalgo, D. R. Cayan, and T. W. Swetnam. 2006. Warming and earlier spring increase western U. S. forest wildfire activity. Science 313:940-943. http://dx.doi. org/10.1126/science.1128834

Western Governors' Association (WGA). 2001. A collaborative approach for reducing wildland fire risks to communities and the environment: 10-year comprehensive strategy. WGA, Denver, Colorado, USA. [online] URL: http://www.forestsandrangelands. gov/resources/plan/documents/7-19-en.pdf

Western Governors' Association (WGA). 2002. A collaborative approach for reducing wildland fire risks to communities and the environment: 10-year comprehensive strategy implementation plan. WGA, Denver, Colorado, USA. [online] URL: http://www. forestsandrangelands.gov/resources/plan/documents/11-23-en.pdf

Wiek, A., L. Withycombe, and C. L. Redman. 2011. Key competencies in sustainability: a reference framework for academic program development. Sustainability Science 6:203-218. http://dx.doi.org/10.1007/s11625-011-0132-6

Williams, J. 2013. Exploring the onset of high-impact mega-fires through a forest land management prism. Forest Ecology and Management 294:4-10. http://dx.doi.org/10.1016/i.foreco.2012.06.030

Young, O. R. 2002. The institutional dimensions of environmental change: fit, interplay, and scale. The MIT Press, Cambridge, Massachusetts, USA.
Young, O. R., L. A. King, and H. Schroeder, editors. 2008. Institutional and environmental change. Principal findings, applications, and research frontiers. The MIT Press, Cambridge, Massachusetts, USA. 